\title{
Ethnopharmacology, Ecological Requirements, Antioxidant and Antimicrobial activities of Perovskia abrotanoides Karel. Extract for Vaginal Infections From Semnan Province
}

\author{
Mohammad Ghafourian $^{1}$, Masoumeh Mazandarani ${ }^{2 \star}$
}

\begin{abstract}
Objectives: Perovskia abrotanoides Karel. is an aromatic plant cultivated in North of Iran, which has been used as anti-inflammatory, sedative, and antiinfective. This work intended to determine the ecological requirements, antioxidant and antimicrobial activities of P. abrotanoides Karel. extract from Semnan province (North of Iran).

Materials and Methods: Aerial parts of plant in bloom were collected from Tash Mountain $(2120 \mathrm{~m})$ in September, 2014. Some ecological requirements and traditional data were obtained from rural people. Ethanol extracts of plant were obtained by maceration method; total flavonoid (TF) and total phenols (TP) were measured by spectrophotometry; antioxidant capacity was measured by TAC, RP, and DPPH; and the antimicrobial activity was studied against some microorganisms using well method and minimum inhibitory concentration (MIC)assay.

Results: Field observations showed that the P. abrotanoides Karel. is one of the wild growing herbs in the feet of the mountain in Semnan province (2000-2700 m). This area has dry cold climate type, with annual raining of $280 \mathrm{~mm}$, temperature rate of 15.5 ${ }^{\circ} \mathrm{C}$, and sandy clay loam soil $(\mathrm{Ec}=0.9$ and $\mathrm{pH}=7.1)$. Plant extract was rich source of TF $(84.2 \pm 0.4 \mathrm{mg} \mathrm{QUE} / \mathrm{g})$ and TP contents ( $143.4 \pm 0.2 \mathrm{mgGAE} / \mathrm{g}$ ) and had good antioxidant activity $\left(\mathrm{IC}_{50}=15.03 \pm 1.2 \mathrm{mg} / \mathrm{mL}\right.$ ) especially in DPPH method. Candida albicans, Staphylococcus aureus, Staphylococcus epidermidis, Bacillus cereus, and Enterococcus faecalis were the most sensitive microorganisms with inhibition zones of 34, 32, 28, 21, $19 \mathrm{~mm}$ and MIC values of 58, 45, 53, 63, and $85 \mathrm{mg} / \mathrm{mL}$, respectively.

Conclusion: Perovskia abrotanoides Karel. has the potential productivity of TP and TF constituents with suitable anti-Candida, antibacterial and antioxidant activities. Therefore it can be used as natural antiinfective to treat many infectious diseases such as vaginal infections.

Keywords: Antioxidant, Antimicrobial, Vaginal infection, Ecology, Ethnopharmacology, Perovskia abrotanoides Karel., North of Iran
\end{abstract}

\section{Introduction}

Reactive oxygen species (ROS) can induce many current inflammatory and infectious disorders (atherosclerosis, infection, cancer, arthritis, hypertension, diabetes, Alzheimer and Parkinson diseases). Therefore natural antioxidant and antimicrobial byproducts of medicinal plants are very useful in the prevent on and treatment of many infections. Some of these byproducts are classified as antioxidants, anti-fungal, and antibacterial, because they can produce many ranges of secondary metabolites (terpenoides, flavonoid, and phenolic components), and can play a main role in inhibiting and scavenging the free radicals as antipathogen, anti-inflammatory and anticancer. Thus, the global trend is toward investigation and screen of natural antioxidants from wild medicinal plants to prevent and treat many current infectious diseases ( 1$)$.

Aromatic plants like many Lamiaceae species have been used for centuries as the source of valuable natural antioxidants in vegetable, food, and drugs in traditional medicine. Therefore, many recent researchers have been interested in chemical extraction, antioxidant and their anti-microorganism properties (2-4).

Perovskia abrotanoides Karel. with local name "wisk", belonging to Lamiaceae family, grows in mountainous regions of Semnan, Golestan, Isfahan, Khorasan, and Mazandran provinces (5), as well as Afghanistan, Pakistan, and Turkmenistan $(5,6)$. The essential oil composition, antifungal, antibacterial, anthelmintic, antinociceptive and antioxidant activities of $P$. abrotanoides have been studied previously (7-10). They have reported phenolic, flavonoid, and terpenoide components (thymol, menthol, carvacrol, $\gamma$-terpinene 4-ol, and p-cymene) in essential oil of perovskia, which can induce high antioxidant and antimicrobial activities against microorganisms $(3,11,12)$. In this regard, this work intended to determine the ecological requirements, antioxidant and antibacterial activities of P. abrotanoides Karel. extracts from Tash mountainous 
region in Semnan province.

Ecological Requirements

The main ecological requirements of $P$. abrotanoides Karel. and its ethnopharmacological knowledge were obtained from many field observations, and natural habitats of this plant (Tash village - $2020 \mathrm{~m}$ ). This region is located in Southeast of Semnan province, in the latitude of $36^{\circ} 37^{\prime}$ $24^{\prime \prime}$ to $36^{\circ} 34^{\prime} 28^{\prime \prime}$ and longitude of $54^{\circ} 35^{\prime} 26^{\prime \prime}$ to $54^{\circ} 24^{\prime}$ $32^{\prime \prime}$ bordering the Alborz area with sandy clay loam soils. Its average height is 600 to $2750 \mathrm{~m}$ above sea level in dry cold climate with average rainfall of $305 \mathrm{~mm} / \mathrm{y}$ and a mean temperature of $-2 / 8^{\circ} \mathrm{C}$ (January to February) and $17 / 3^{\circ} \mathrm{C}$ (July to August).

\section{Plant Material and Extract Preparation}

The aerial parts of $P$. abrotanoides Karel. in bloom were collected in September 2013 from Tash Mountain (2020 $\mathrm{m})$. A voucher specimen of plant was identified and preserved (No. HRCMP:129), and deposited at the Herbarium of RCMP (Research Center of Medicinal plants, Islamic Azad University, Gorgan branch, Golestan province, Iran). The aerial parts of plant in bloom was shade-dried, powdered, and stored at $4^{\circ} \mathrm{C}$ until in vitro studies. One gram of plant parts with $100 \mathrm{~mL}$ ethanol $80 \%$ were extracted by maceration. Extracts were filtered with Whatman No. 1 filter paper. The filtrates obtained from extracts were evaporated in dry rotary evaporator at $40^{\circ} \mathrm{C}$ and were stored at $4^{\circ} \mathrm{C}(13)$.

\section{Chemicals}

2,2'-diphenyl-1-picrylhydrazyl (DPPH) was purchased from Sigma ChemicalCo.(St., Louis, USA). BHT (butylated hydroxytoluene), BHA (butylated hydroxyanisole), and methanol were purchased from Merck Co. (Germany).

\section{Antioxidant Activity Tests}

\section{Reducing Power Assay}

A dried extract $(12.5-1000 \mu \mathrm{g})$ in $1 \mathrm{~mL}$ of the corresponding solvent was combined with $2.5 \mathrm{~mL}$ of phosphate buffer (0.2 M, pH 6.6) and $2.5 \mathrm{~mL}$ of potassium ferricyanide $(\mathrm{K} 3 \mathrm{Fe}(\mathrm{CN}) 6 ; 10 \mathrm{~g} / \mathrm{L})$. Then the above mixture was incubated at $50^{\circ} \mathrm{C}$ for 30 minutes. After that, $2.5 \mathrm{~mL}$ of trichloroacetic acid $(100 \mathrm{~g} / \mathrm{L})$ was added and then the mixture was centrifuged at $1650 \mathrm{~g}$ for 10 minutes. Finally, $2.5 \mathrm{~mL}$ of the supernatant solution was mixed with 2.5 $\mathrm{mL}$ of distilled water and $0.5 \mathrm{~mL}$ of $\mathrm{FeCl}(1 \mathrm{~g} / \mathrm{L})$, and the samples' absorbance was measured at $700 \mathrm{~nm}$ (14).

\section{1,1-diphenyl-2-picryl hydrazyl radical scavenging capacity assay}

The ability of the extracts for free radical scavenging was assessed by the method suggested by Arabshahi et al (14). Briefly, $1 \mathrm{~mL}$ of a $1 \mathrm{mM}$ methanolic solution of DPPH was mixed with $3 \mathrm{~mL}$ of extract solution in methanol (containing 12.5-1000 $\mu \mathrm{g}$ of dried extract). The mixture was then vortexed vigorously and left for 30 minutes at room temperature in the dark. The absorbance was measured at $517 \mathrm{~nm}$ and activity was expressed as percentage of DPPH scavenging relative to control using the following equation:

DPPH scavenging activity $(\%)=[($ Abs control - Abs sample) / Abs control] $\times 100$

Total Antioxidant Capacity

Total antioxidant capacity of the extracts was evaluated according to the procedure described by Arabshahi et al (14). A $0.1 \mathrm{~mL}$ of sample (plant extract) was combined with $1 \mathrm{~mL}$ of reagent solution ( $0.6 \mathrm{M}$ sulfuric acid, $28 \mathrm{mM}$ sodium phosphate, and $4 \mathrm{mM}$ ammonium molybdate). The tubes containing the reaction solution were incubated in a thermal block at $95^{\circ} \mathrm{C}$ for 90 minutes. Then, the absorbance of the solution was measured at $695 \mathrm{~nm}$ using a UV-VIS spectrophotometer (UVmini-1240) against blank after cooling to room temperature. Methanol (0.3 $\mathrm{mL}$ ) in the place of extract was used as the blank. The total antioxidant activity was expressed as ascorbic acid equivalent. The calibration curve was prepared by mixing ascorbic acid $(1000,500,250,125,62.5$ and $31.25 \mu \mathrm{g} / \mathrm{mL})$ with ethanol (80\%) (14).

\section{Bacterial Strains}

Ten microbial species ( 1 yeast and 8 gram-positive and 1 gram-negative bacteria) were analyzed. The bacteria (numbers 1 to 9) were taken from international collections (they were sensitive to the antibiotics listed below). The yeast sample (number 10) and the bacteria (numbers 1 to 9), obtained from the Microbiology Laboratory, Golestan University of Medical Sciences, were: Shigella dysenteriae (PTCC1188), Pseudomonas aeruginosa (PTCC1430), Escherichia coli (PTCC1399), Staphylococcus aureous (PTCC1431), Bacillus cereus (PTCC1015), Salmonella typhimurium (PTCC1596), Staphylococcus epidermidis (PTCC1114), Enterococcus faecalis (PTCC1393), and Klebsiella pneumoniae (PTCC1291), and one fungal isolate was Candida albicans (PTCC5027).

\section{Antimicrobial Potential of the Plant Extracts}

The bacterial cultures were grown in Brain Heart Infusion liquid medium at $37^{\circ} \mathrm{C}$. After 8 hours of growth, each microorganism was inoculated on the surface of MuellerHinton agar (Pronadisa, Madrid) plates. Subsequently, filter paper discs $(6 \mathrm{~mm}$ in diameter) saturated either with plant extract $(50 \mu \mathrm{L})$ were placed on surface of each inoculated plate. The plates were incubated at $37^{\circ} \mathrm{C}$ for 24 hours. After this period, their inhibition zone could be observed. Overall, cultured bacteria with halos equal to or greater than $7 \mathrm{~mm}$ were considered susceptible to either the tested extract. DMSO (dimethyl sulfoxide) was used to dissolve the extracts in the culture media when necessary. 
The controls were the solvents used for each extract and they showed no inhibitions in preliminary studies.

An amount of $0.01 \mathrm{~mL}$ of each bacterial suspension, equivalent to McFarland tube No. 0.5 (108 CFU/mL), was inoculated on the agar of every well. The culture plates were then incubated at $37^{\circ} \mathrm{C}$ for 24 hours. The minimum inhibitory concentration (MIC) was defined as the lowest concentration at which no visible growth was observed (15). The Mueller-Hinton agar containing DMSO without plant extract was used as negative control while gentamycine was used as positive control.

\section{Statistical Analysis}

The statistical analyses were carried out in triplicate and given as the mean \pm standard deviation (SD). The data of all experiments were analyzed using Analysis of variance (ANOVA) which was used for comparison of the effectiveness of the anti-bacterial activities. Differences were considered significant at $P<0.05$.

\section{Results}

Results of many field observations showed that in Semnan province, the vegetative growth of $P$. abrotanoides Karel. starts from late of May to early September. It blooms from July to late of August and the ethnopharmacological survey of plant showed that the P. abrotanoides Karel. is the most wild aromatic perennial herb, which often grows in inclined and sunny places around Tash grassland mountain (2000-2700 m). This grassland mountain is 70 $\mathrm{km}$ far from Shahrud city, with annual raining of $280 \mathrm{~mm}$, annual temperature of $15.5^{\circ} \mathrm{C}$ in dry cold climate, and sandy clay loam soil, with $\mathrm{Ec}=0.9$ and $\mathrm{pH}=7.1$. This plant with local name of "Wisk", has been used traditionally lonely or in combination with other medicinal herbs (Thymus carmanicus, Artemisia sieberi, Mentha longifolia, and Ferula gummosa) as an antispasmodic, sedative, antiinflammatory, antihelmintic, antifungal and anti-infective to treat rheumatism, migraine, UTI, leishmaniasis, dysmenorrhoea, and vaginal and dermal infections. There are some examples as below:

To treat dermal infection: Preliminary data showed that the ointment which was produced by compounds of some medicinal plants such as T. carmanicus, M. longifolia, Onosma dichroanthum, Malva neglecta, and Hypericum perforatum as with the extract of $P$. abrotanoides has a strong potential as anti-inflammatory, antifungal, antibacterial, and anti-infective to treat dermal infections and heal wounds such as burned skin.

Sedative and anti-inflammatory: The massage of the oil of P. abrotanoides, Stachys inflata, A. sieberi, and Capsicum annuum as anti-spasmodic, anti-inflammatory and sedative is to treat rheumatism, backache, sciatica, and gout.

Vaginal infections: The suppository tampon (the decoction of $P$. abrotanoides with the fruit of Juniperus sabina,
M. longifolia, and the fruit of Cupressus and Quercus ) injected to vagina is consumed for the treatment of vaginal infections.

Anti-helmentic: consumption of the drug combined with pomegranate extract, F. gummosa, Artemisia annua, $P$. abrotanoides, and Peganum harmala in morning fasting.

According to (Tables 1 and 2, phytochemical and antioxidant assays showed that the content of total phenols $(\mathrm{TP}=143.4 \pm 0.2 \mathrm{mg} \mathrm{GAE} / \mathrm{g}$ ) and total flavonoids (TF $=84.2 \pm 0.4 \mathrm{mg}$ QUE/g) in aerial parts of P. abrotanoides Karel., had good antioxidant activity with $\mathrm{IC}_{50}=15.03 \pm 1.2$ $\mathrm{mg} / \mathrm{mL}$, especially in DPPH method, which had lower content of $\mathrm{IC}_{50}$ in free radical scavenging.

Inhibition zones (IZ) and MIC values of the ethanol extract of $P$. abrotanoides Karel. in comparison with 2 standard antibiotics (BHT and BHA) were presented in Table 1 . The results indicated that the ethanol extract of plant exhibited moderate to high level of antibacterial activity on tested bacteria with IZ $(12.4 \pm 0.5$

- 34. $1 \pm 0.4 \mathrm{~mm}$ ), respectively. C. albicans, $S$. aureus, $S$. epidermidis, B. cereus, E. faecalis, and E. coli were the most sensitive tested microorganisms with inhibition zones of $34,32,28,21$, and $19 \mathrm{~mm}$ and MIC values of 58, 45, 53,63 , and $85 \mathrm{mg} / \mathrm{mL}$, respectively, and other bacteria (P. aeruginosa, E. faecalis, K. pneumonia, Salmonella and Shigella) showed moderate effects against the plant extract, respectively.

\section{Discussion}

The resistance of pathogenic fungi, including C. albicans

Table 1. Antioxidant Activity of Perovskia abrotanoides Karel. in Tash Mountain in Semnan Province (2020 m)

\begin{tabular}{lccc}
\hline $\begin{array}{l}\text { Antioxidant } \\
\text { Activity, } \mathrm{IC}_{50}(\mu \mathrm{g} / \mathrm{mL})\end{array}$ & Aerial Parts & BHA & BHT \\
\hline TAC & $45.3 \pm 0.1$ & & \\
RP & $32.3 \pm 0.31$ & $3.85 \pm 0.351$ & $3.13 \pm 0.404$ \\
DPPH & $15.03 \pm 1.2$ & & \\
\hline
\end{tabular}

Table 2. In Vitro Antimicrobial Activity and MIC Values in Ethanol Extract of Perovskia abrotanoides Karel. From Tash Mountainous Region (2020 m), Semnan Province (North of Iran)

\begin{tabular}{lccc}
\hline Microorganisms & $\begin{array}{c}\text { IZ } \\
\text { (Mean } \pm \text { SD) }\end{array}$ & $\begin{array}{c}\text { MIC } \\
(\mu \mathrm{g} / \mathrm{mL})\end{array}$ & Gentamycin \\
\hline Staphylococcus aureus & $32.1 \pm 0.4$ & 45.1 & 16.7 \\
Staphylococcus epidermidis & $28.4 \pm 0.3$ & 53.2 & 14.7 \\
Bacillus cereus & $21.6 \pm 0.5$ & 63.7 & 16.5 \\
Enterococcus faecalis & $19.1 \pm 0.1$ & 85.5 & 9.6 \\
Escherichia coli & $17.4 \pm 0.2$ & 102.1 & 11 \\
Pseudomonas aeroginosa & $15.2 \pm 0.3$ & 124.1 & 9 \\
Klebsiella pneumonia & $12.5 \pm 0.1$ & 132.9 & -- \\
Salmonella typhimurium & $12.7 \pm 0.1$ & 172 & 11 \\
Shigella dysenteriae & $12.4 \pm 0.5$ & 134.3 & 11 \\
Candida albicans & $34.1 \pm 0.4$ & 58.3 & 18 \\
\hline
\end{tabular}

Abbreviations: IZ, Inhibition zones; MIC, minimum inhibitory concentration. 
and other species isolated from patients, against antifungal agents has increased (16). Around $75 \%$ of adult women have at least one episode of vaginal infection during their life, with prevalence of C. albicans from $70 \%$ to 90\%). Many traditional medications derived from plant sources including the wild aromatic medicinal plants, especially from mountainous regions, are still being used; therefore, they can be renewable candidates in nature and major sources of new anti-oxidant and anti-pathogenic compounds (1).

According to Tables 1 and 2, it was shown that the content of total phenols $\left(\mathrm{TP}=81.7+\_0.3 \mathrm{GAE} / \mathrm{g}\right)$ and total flavonoids (TF= $34.2 \pm 0.8 \mathrm{QUE} / \mathrm{g}$ ) in aerial parts of $P$. abrotanoides Karel. had good antioxidant activity with $\mathrm{IC}_{50}$ $=21.8 \pm 0.1 \mu \mathrm{g} / \mathrm{mL}$, especially in DPPH method, which had higher content of $\mathrm{IC}_{50}$ in free radical scavenging. The ethanol extract of plant exhibited moderate to high level of antibacterial activity against tested bacteria with IZ $(12.1 \pm 0.8-27.7 \pm 0.8 \mathrm{~mm})$ respectively, except for Shigella dysenteriae, which is the gram-negative resistant bacterium. But other bacteria (S. aureus, S. epidermidis, $B$. cereus, and E. faecalis) and Candida albicans were the most sensitive with inhibition zones of $27,22,16$, and $15 \mathrm{~mm}$, and MIC values of $60,68,53$, and $83 \mathrm{mg} / \mathrm{mL}$, respectively.

In many similar researches, it was reported that the natural antioxidants (terpenoides, phenolic compounds, and flavonoids) in many aromatic mountainous plants, which can play a main role in free radical scavenging, positively reduce risk of developing infectious, inflammatory, diabetic, cancer, hypertension, and other current diseases. Therefore, there is a growing interesting to identify natural antioxidants in wild aromatic plants with strong radical scavenging activities (1).

In relation to these results, to confirm the traditional uses of these plants in Tash village as anti-inflammatory, antihelmentic, and antiinfective in the treatment of vaginal infections and leishmaniasis, other researches showed that the terpenoides and polyphenols present in the extracts of P. abrotanoides Karel., M. longifolia, F. gummosa, T. carmanicus, A. sieberi, A. annua, P. harmala, and J. sabina can be used as anti-infectious, anti-inflammatory, antifungal, and sedative (1,7-10). Hence, the current study was conducted on rich secondary metabolites of abovementioned plants and their antioxidant activity due to their traditional medicinal uses in Golestan and Semnan provinces as sedative, antispasmodic, anti-infectious, and anti-inflammatory in the treatment of many vaginal and dermal infections.

According to the reports, in Iranian traditional medicine, traditional system of medicine in Pakistan, and traditional medicine in Turkey, applying a poultice of $P$. abrotanoides, A. sieberi, J. sabina, and M. longifolia with sesame oil has been attended in the treatment of many dermal wounds and leishmaniasis $(8,17)$. The extracts of Leaves of $P$. abrotanoides with the black fruit of $J$. sabina and the gums of F. gummosa have been used as pain killer, anti inflammatory and anti infective to treat UTI and urinary and vaginal infections in Golestan and Mazandaran provinces $(1,10)$.

In similar reports, essential oils rich in phenolic compounds and terpenoides such as carvacrol, $\gamma$-terpinene, 1,8-cineole, terpinene 4-ol, $\alpha$ and $\beta$-pinene, camphor and thymol were reported to possess high levels of antimicrobial activity. In fact, other constituents such as camphen, 1,8-cineol, $\gamma$-terpinene, and terpinene 4-ol have been considered to display relatively good activity due to their possible antagonistic effects, anti-inflammatory, anti-infective, and sedative to treat cold, flu, arthritis, rheumatism, vaginal infection, UTI, and leishmaniasis (12).

In confirmation of our data, many similar researches have shown that the antioxidant and antimicrobial activities of other plant species such as $P$. abrotanoides, M. longifolia, Thymus spp., A. annua, A. sieberi, J. sabina, P. harmala, and Punica granatum have been previously studied and many of them have reported that the antimicrobial activity of essential oil and the extracts, relative to their main phenolic components (thymol, menthol, carvacrol, $\gamma$-terpinene terpinene 4 -ol and p-cymene), has shown a high inhibitory effect against a wide range of microorganisms $(3,11,18-20)$.

Antihelmintic and anti-fungal properties of $P$. abrotanoides, J. sabina, F. gummosa, and T. carmanicus is due to the presence of many phenolic, flavonoid, and terpinene compounds such as thymol, menthol, sabinene, camphor, 1,8-cineole, verbenone, alpha terpineol, terpinolene, and gamma terpinene have been found in many essential oils of these plants as anti-inflammatory, anti-infective, anti-fungal, antioxidant, anti-tumor, antihelmintic, and anti-pathogenic to treat many infectious diseases such as dermal, vaginal, and urinary infections, arthritis muscle spasm and dysmenorrhea (20-26). Therefore, our results in this paper and other researches can confirm the traditional consumption of these medicinal plants in North provinces of Iran (Golestan and Semnan) as anti-spasmodic, anti-inflammatory, antihelmintic, antifungal, and anti-infective to treat UTI, vaginal infection, depression, and stress of arthritis and muscle spasm in pregnant women.

These data indicate that the P. abrotanoides Karel. extract and its constituents (terpinen-4-ol, $\gamma$-terpinene, carvacrol, verbenone, terpinolene, and sabinene) may be applied as antibacterial, antifungal, and antioxidant agents and moreover as an anticancer agent. Thus the literature has described that the antibacterial and antioxidant activities of $P$. abrotanoides can depend on its terpenoids and flavonoids (terpinen-4-ol, $\gamma$-terpinene, and carvacrol) in essential oil or extract $(21,23,24,27)$.

In the report of Tolossa et al (15), the $\gamma$-terpinene, thymol, p-cymene, carvacrol, pulegone, isomenthone, 
and piperitone oxide were respectively shown as the major constituents of Satureja thymbra, P. abrotanoides, $T$. carmanicus, A. sieberi, and F. gummosa which grow in wild mountainous regions and have strong antioxidant and antimicrobial activities against fungi and tested bacteria, respectively $(1,15)$.

\section{Conclusion}

Our results in this study, first, can confirm the traditional uses of $P$. abrotanoides Karel. as antispasmoic, sedative, and antinfective in treating rheumatism, vaginal infection, UTI, and dysmenorrhoea and then prove that the ethanol extract of plant like other mentioned Thymus, juniperus, and Ferula species can have great potential of antimicrobial, antifungal and antioxidant to be used as natural antimicrobial and antioxidant drugs and additives in the preservation of processed food and drug industry. These data indicate the possibility that Perovskia abrotanoides extracts and its constituents may be applied as antibacterial and antifungal agents and moreover as an antivaginal agent for novel anti-inflammatory and antioxidant activities.

\section{Acknowledgments}

The authors are grateful to RCMP (Research Center of Medicinal plants), Islamic Azad University, Gorgan branch. We also thank prof. Ghaemi for his assistance in methodology section and for his comments which greatly improved the manuscript.

\section{Ethical Issues}

The local ethics committee approved the study.

\section{Conflict of Interests}

None.

\section{Financial Support}

Self-funded.

\section{References}

1. Mazandarani M, Zeinali Z, Ghafourian M. Autecology essential oil composition, antibacterial, anti candidacies and ethnopharmacological survey of Ferula gummosa L. as anti infection to treat of vaginal infections in traditional medicine of Razavi Khorasan province (North East of Iran). Crescent Journal of Medical and Biological Sciences. 2015; 2(2):42-47.

2. Tepe B, Daferera D, Sokmen A, Sokmen M, Polissiou M. Antimicrobial and antioxidant activities of the essential oil and various extracts of Salvia tomentosa Miller (Lamiaceae). Food Chem. 2005;90(3):333-340. doi: 10.1016/j.foodchem.2003.09.013.

3. Sadeghi I, Yousefzadi M, Behmanesh M, Sharifi M, Moradi A. In vitro cytotoxic and antimicrobial activity of essential oil from Satureja intermedia. Iran Red Crescent Med J. 2013;15(1):70-74. doi:10.5812/ircmj.4989.

4. Mazandarani M, Mirdeilami SZ, Pessarakli M. Essential oil composition and antibacterial activity of
Achilleamillefolium L. from different regions in North east of Iran. J Med Plant Res. 2013;7(16):1063-1069. doi: 10.5897/JMPR12.961

5. Mozaffarian VA. Dictionary of Iranian plant names.Tehran, Iran: Farhang Moaser; 1996. [Persian].

6. Morteza-Semnani K. The essential oil composition of Perovskia abrotanoides from Iran. Pharm Biol. 2004;42(3):214-216. doi:10.1080/13880200490514078.

7. Hosseinzadeh H, Amel S. Antinociceptive effects of the aerial parts of Perovskia abrotanoides extracts in Mice. Iran Red Crescent Med J. 2001;4(1):15-17.

8. Moallem SA, Niapour M. Study of embryotoxicity of Perovskia abrotanoides, an adulterant in folk-medicine, during organogenesis in mice. J Ethnopharmacol. 2008;117(1):108-114. doi:10.1016/j.jep.2008.01.020.

9. Ballabh B, Chaurasia OP, Ahmed Z, Singh SB. Traditional medicinal plants of cold desert Ladakh-used against kidney and urinary disorders. J Ethnopharmacol. 2008;118(2):331339. doi:10.1016/j.jep.2008.04.022.

10. Esmaeili S, Naghibi F, Mosaddegh M, Sahranavard S, Ghafari S, Abdullah NR. Screening of antiplasmodial properties among some traditionally used Iranian plants. J Ethnopharmacol. 2009;121(3):400-404. doi:10.1016/j. jep.2008.10.041

11. Sonboli A, Fakhari A, Kanani MR, Yousefzadi M. Antimicrobial activity, essential oil composition and micromorphology of trichomes of Satureja laxiflora C. Koch from Iran. Z Naturforsch C. 2004;59(11-12):777-781.

12. Mazandarani $M$, Ghafourian $M$, Khormali A. Ethnopharmacology, antibacterial and antioxidant activity of Dittrichia graveolens (L.) W. Greuter. which has been used as remedies antirheumatic, anti-inflammation and antiinfection against leishmaniasis in the traditional medicine of Gorgan, Iran. Crescent Journal of Medical and Biological Sciences. 2014;1(4):125-129.

13. Pourmorad F, Hosseinimehr SJ, Shahabimajd N. Antioxidant activity, phenol and flavonoid contents of some selected Iranian medicinal plants. Afr J Biotechnol. 2006;5(11):1142-1145.

14. Arabshahi-Delouee S, Urooj A. Antioxidant properties of various solvent extracts of mulberry (Morus indica L.) leaves. Food Chem. 2007;102(4):1233-1240. doi:10.1016/j. foodchem.2006.07.013.

15. Tolossa K, Asres K, El-Fiky FK, Singab ANB, Bucar F. Composition of the essential oils of Satureja abyssinica ssp. abyssinica and Satureja paradoxa: their antimicrobial and radical scavenging activities. Journal of Essential Oil Research. 2007;19(3):295-300. doi:10.1080/10412905.2007 .9699285.

16. Cetin H, Erler F, Yanikoglu A. A comparative evaluation of Origanum onites essential oil and its four major components as larvicides against the pine processionary moth, Thaumetopoea wilkinsoni Tams. Pest Manag Sci. 2007;63(8):830-833. doi:10.1002/ps.1401.

17. Jaafari MR. Hooshmand S, Samiei A, Hossainzadeh H. Evaluation of leishmanicidal effect of Perovskia abrotanoides Karel. root extract by in vitro leishmanicidal assay using promastigotes of Leishmania major. Pharmacologyonline. 2007;1:299-303.

18. Vagionas K, Graikou K, Ngassapa O, Runyoro D, Chinou I. Composition and antimicrobial activity of the essential oils of three Satureja species growing in Tanzania. Food Chem. 2007;103(2):319-324. doi:10.1016/j.foodchem.2006.07.051. 
19. Oke F, Aslim B, Ozturk S, Altundag S. Essential oil composition, antimicrobial and antioxidant activities of Satureja cuneifolia Ten. Food Chem. 2009;112(4):874-879. doi: 10.1016/j.foodchem.2008.06.061

20. Mazandarani M, Makari S, Bajian GR, Zarghami Moghaddam P, Abrodi M. Evaluation of phytochemical and antioxidant activity in different parts of Heracleum gorganicum Rech. in Golestan province of Iran. Iran J Plant Physiol. 2011;2:381-386.

21. Ashraf SN, Zubair M, Rizwan K, et al. Compositional studies and Biological activities of Perovskia abrotanoides Kar. oils. Biol Res. 2014;47:12. doi:10.1186/0717-6287-4712.

22. Sayyah M, Kamalinejad M, Hidage RB, Rustaiyan A. Antiepileptic Potential and composition of the fruit essential oil of Ferula gummosa Boiss. Iran Biomed J. 2009;5:69-72.

23. Sajjadi SE, Mehregan I, Khatamsaz M, Asgari G. Chemical composition of the essential oil of Perovskia abrotanoides Karel. growing wild in Iran. Flavour Fragr J. 2005;20(4):445446. doi:10.1002/ffj.1508
24. Hart PH, Brand C, Carson CF, Riley TV, Prager RH, Finlay-Jones JJ. Terpinen-4-ol, the main component of the essential oil of Melaleuca alternifolia (tea tree oil), suppresses inflammatory mediator production by activated human monocytes. Inflamm Res. 2000;49(11):619-626. doi:10.1007/s000110050639.

25. Golshani S, Karamkhani F, Monsef-Esfehani HR, Abdollahi M. Antinociceptive effects of the essential oil of Dracocephalum kotschyi in the mouse writhing test. J Pharm Pharm Sci. 2004;7(1):76-79.

26. Southwell I, Russell M, Smit RL, Brophy JJ. Day J. Melaleuca Teretifolia, a Novel Aromaticand Medicinal Plant frome Australia. Medicinal and Aromatic Plants - Volume 3: Perspectives in Natural Product Chemistry. 2008;49(11): 619-626.

27. Tabatabaei-Raisi A, Delazar A, Khaligi A, Kaviani B, Hashemabadi D. Variability of essentials oils of various parts of Satureja sahendica Bornm. and their antioxidant activity. International Journal of Botany. 2008;4(2):245-248

Copyright $\odot 2017$ The Author (s); This is an open-access article distributed under the terms of the Creative Commons Attribution License (http://creativecommons.org/licenses/by/4.0), which permits unrestricted use, distribution, and reproduction in any medium, provided the original work is properly cited. 